\title{
BUENAS PRÁCTICAS TIC. LA ALFABETIZACIÓN DIGITAL EN MAYORES
}

Resumen: Los equipos informáticos y sus periféricos están diseñados para el uso de un único usuario, constan de un único teclado, ratón; y de una única pantalla. De modo que en una clase de iniciación a la informática, la mejor opción parece ser un equipo por persona. Así, aparentemente, al interactuar individualmente se avanzará más ¿Pero, y si no es posible contar con suficientes medios? ¿Es realmente imprescindible el "monopuesto" para lograr un aprendizaje significativo? Gracias a la experiencia durante varios cursos de alfabetización digital con adultos utilizando una metodología afín a los objetivos expondremos una buena práctica formativa, haciendo frente a factores adversos como la escasez de recursos. Sin lugar a dudas, sin descuidar la psicología del adulto, educando la adquisición de capacidades tecnológicas haciendo a la persona autónoma en su aprendizaje.

Palabras clave: Aprendizaje Significativo, Alfabetización Digital, Buenas Prácticas TIC, Adultos.

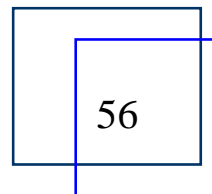

Félix Huelves Martín 


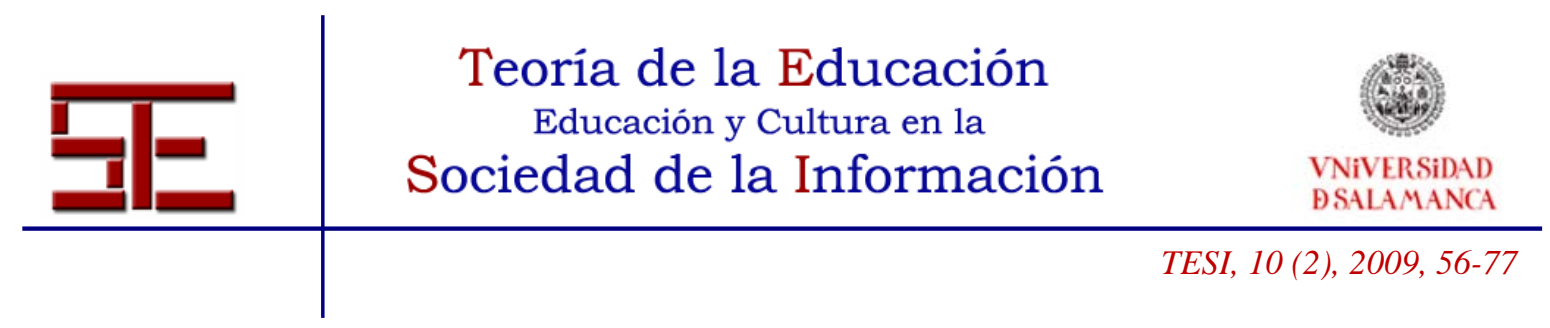

GOOD PRACTICE TIC. DIGITAL LITERACY IN OLDER.

Abstract. Computer equipment and their peripherals are designed for use by a single user, there is only one keyboard, only one mouse, and of course, a single screen. Therefore in the moment to provide a literacy class, the best option seems to be one computer per person. So each student seemed to learn more, have greater interaction with media, and therefore more learning time. But, Is it possible to have the number of computer needed for each student, always? Is it really essential the Single Computers in classroom for effective learning? Thanks to the experience in lot of adults' literacy courses, using a methodology consistent with the goal of learning, we show a good formative experience, which although obvious, it allows us to realize factors such as the shortage of technological resources, adult psychology and the need to educate not only new technological capabilities but also to transmit values essential to ease management in the knowledge society.

Keywords: Computer Literacy, Older People, ICT Good Experience.

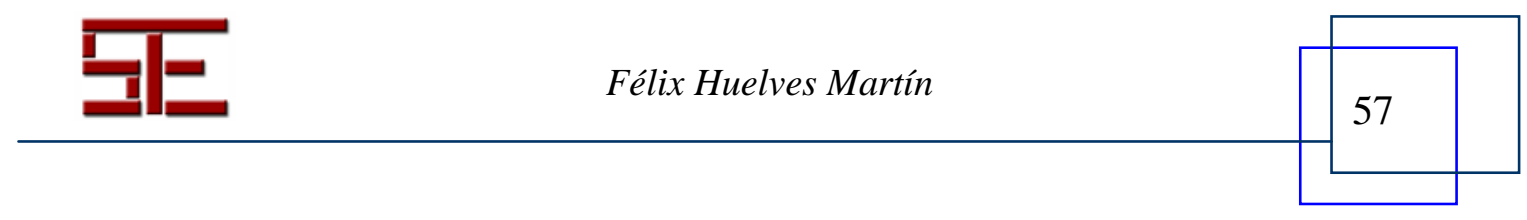




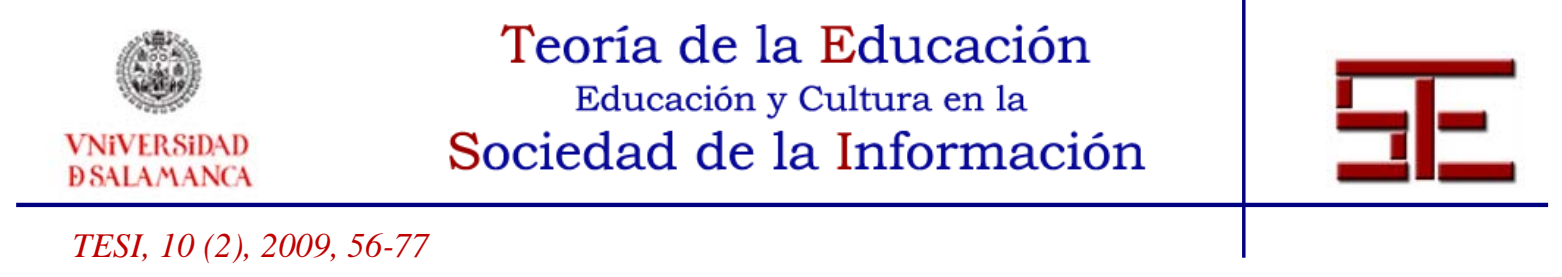

\section{BUENAS PRÁCTICAS TIC. LA ALFABETIZACIÓN DIGITAL EN MAYORES}

Félix Huelves Martín

felix.hm@gmail.com

ICT Education adviser

\section{1.- MARCO CONCEPTUAL}

Sin querer entrar en largas disertaciones teóricas al respecto dado que este artículo quiere basarse en la práctica de las TIC en las aulas con adultos y mayores y su metodología, queremos mencionar los principales factores necesarios a tener en cuenta a la hora de trabajar en la formación informática de esta población.

\subsection{La Memoria en el Adulto Mayor}

Según Montorio Cerrato y Perez Rojo (2006), conforme al avance en la edad

"hay con frecuencia cambios en el funcionamiento cognitivo, especialmente en el de memoria (Craik, 2002) El declive cognitivo comienza a observarse, en la mayoría de la población, entre los 50 y los 60 años. Sin embargo este declive no sucede en todos los individuos ni en todas las áreas.” (p.5.)

Sin embargo como dicen Vega et alt:

"no podemos afirmar rotundamente que la memoria de las personas empeore con la edad [...] las pequeñas pérdidas que se producen en la etapa adulta son fácilmente compensadas por el uso de otras estrategias cognitivas, como por ejemplo, la de prestar más atención inicial al material[...] [en todo caso] por lo que se refiere a la memoria a largo plazo (MLP) en ancianos no enfermos, hay una pérdida que parece no estar tanto en la capacidad para almacenar información, cuanto en la habilidad para recuperarla" (Vega, J.L, Bueno, B \& Buz, J.,1999,p.553)

Estos estudios evidencian que no es tanto una pérdida de memoria y capacidad de almacenamiento o atención, sino la de recuperación. Existen multitud de programas de entrenamiento y estimulación cognitiva que se pueden consultar de forma gratuita en diferentes páginas web que referenciaremos al final de este artículo. Queremos simplemente mencionar que es fundamental por parte del docente incluir en la

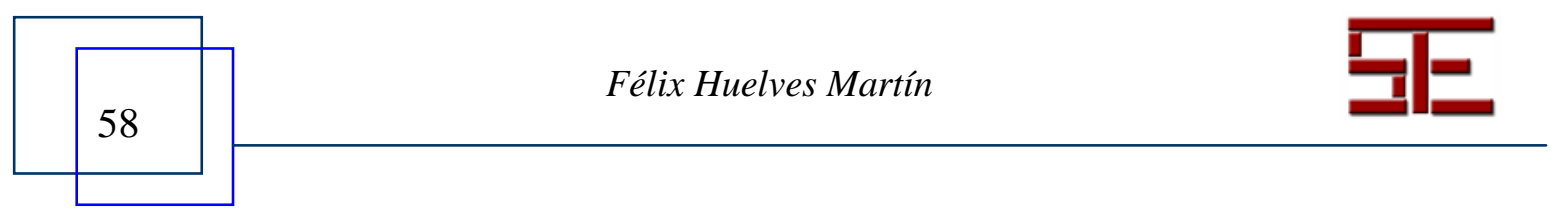




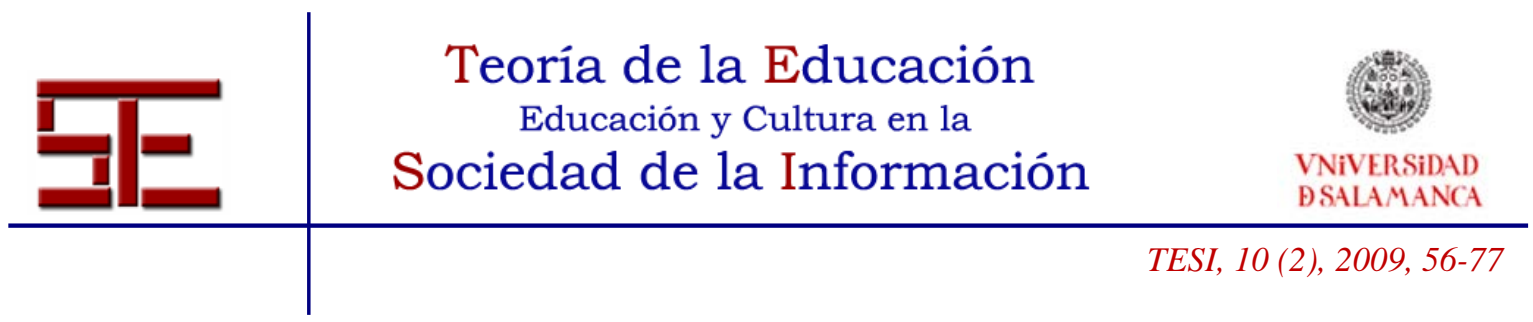

metodología algunos pasos que sistemáticamente permitan hacer frente al olvido, y facilitar el almacenamiento y la recuperación.

Por lo que nuestra metodología se basará en un aprendizaje en espiral que permita cada día retomar lo del día anterior. De esta forma, activaremos el recuerdo de nuestro alumnado, construyendo siempre cada ladrillo de conocimiento, uno sobre otro, asegurando que cada pilar esté bien afianzado, utilizando su propia experiencia como argamasa de una construcción sólida y eficaz. Para ello necesitaremos herramientas de trabajo que nos permitan mezclar estos elementos en el orden adecuado, por lo que nos basaremos en técnicas de aprendizaje constructivista, colaborativo y programas de estimulación cognitiva como los que se pueden consultar de forma gratuita en la página web del IMSERSO: http://imsersomayores.csic.es

\section{2.- La Psicomotricidad en el Adulto Mayor}

Para todos nosotros es evidente que según avance la edad, perdemos algo de salud física, y capacidades motrices, sin embargo comenta "el efecto del elentecimiento motor puede verse notablemente reducido mediante la práctica de tareas concretas y a través de de la práctica de ejercicio físico” (Vega, J.L, Bueno, B \& Buz ,1999, p.551)

Es fundamental que nuestros adultos, en el tema que tratamos, hagan algunos ejercicios de estiramiento y calentamiento de manos, muñecas, y cuello antes de sentarse frente al ordenador, siempre es mejor prevenir que curar.

La ergonomía como la ciencia que estudia la mejor forma de adecuar el hombre y el medio de trabajo para una mayor efectividad en la tarea evitando o minimizando los riesgos sobre la salud, tiene mucho que decir con respecto al material Informático. Existen guías en Internet sobre correcciones posturales en oficinas, y en el uso generalizado para profesionales de la informática que nos aporta documentación de trabajo con el alumnado. Es importante recalcar, todas las veces que sea necesario, la corrección postural con el fin de crear hábitos de higiene y ergonomía básicas:

\subsection{1.- El Uso adecuado del ratón. Pautas básicas.}

- Reposar la mano de forma natural sobre la base del ratón, dejando caer la muñeca, relajada de forma que esté alineada (no torcida) con el ratón.

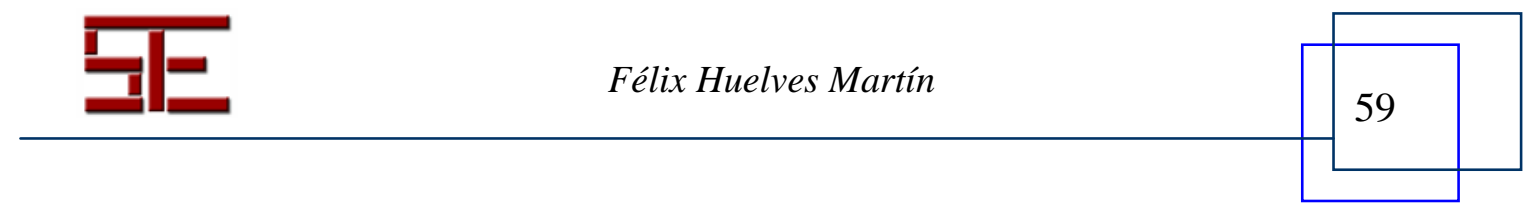




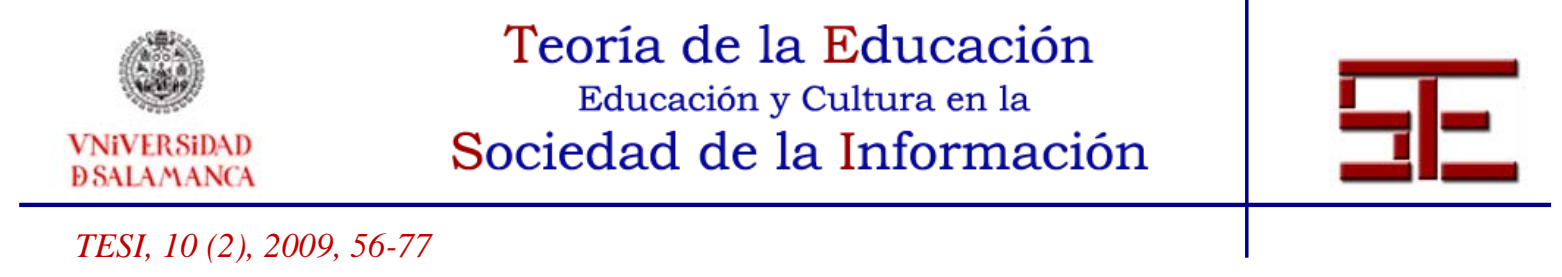

- Depositar el pulgar manteniendo el ratón, sin apretar.

- Coloque, suavemente el índice sobre el botón izquierdo del ratón. Mantenga el índice siempre sobre el botón, aunque no haga clic en el botón.

- Apoyar el antebrazo mientras utiliza el ratón, reduciendo la tensión muscular y ligamentos del brazo y del antebrazo.

- Ajustar la velocidad del ratón (utilizando el programa de configuración del ratón de Windows) para cada nivel del alumnado.

- Mantenga su muñeca en línea recta con el ratón y el antebrazo. Esto reducirá la presión en el túnel carpiano así como el riesgo de lesiones.

- Mueva la mano (no la muñeca) cuando utilice el ratón, y para el principiante, todo el brazo si es necesario, pero apoyado siempre sobre la mesa. Reducirá tensión muscular en ligamentos de muñeca, cuello, y hombros.

- Evitar usar alfombrillas, que limitan conceptualmente el área de campo del ratón. Puesto que el alumnado cree que debe mantener el dispositivo dentro de la alfombrilla para que funcione.

\subsubsection{El Uso adecuado del Teclado.}

Según las pautas del Servicio de Prevención de Riesgos Laborales de la Universidad de Jaén: "Entre el teclado y el borde de la mesa debe quedar un espacio de al menos $10 \mathrm{~cm}$. para apoyar las muñecas” (Servicio de Prevención de Riesgos Laborales de la Universidad de Jaén, 2008, p.4)

Y de modo general, el INSHT:

“Situar el teclado y el ratón a una altura y en una posición más adecuada a las características antropométricas del trabajador; facilitando el apoyo de los pies sobre el suelo.

Trabajar de pie o sentado, fomentando así el confort de la espalda, reduciendo la carga muscular y los problemas musculoesqueléticos.

Soportar correctamente el cuerpo y cambiar de posición, favoreciendo la circulación. Utilizar el equipo diversas personas con características físicas diferentes, permitiendo, debido a la versatilidad en sus ajustes, cambios de postura y movimientos frecuentes. Además, proporciona una correcta posición de las muñecas.” (Instituto Nacional de Seguridad e Higiene el Trabajo, p.6)

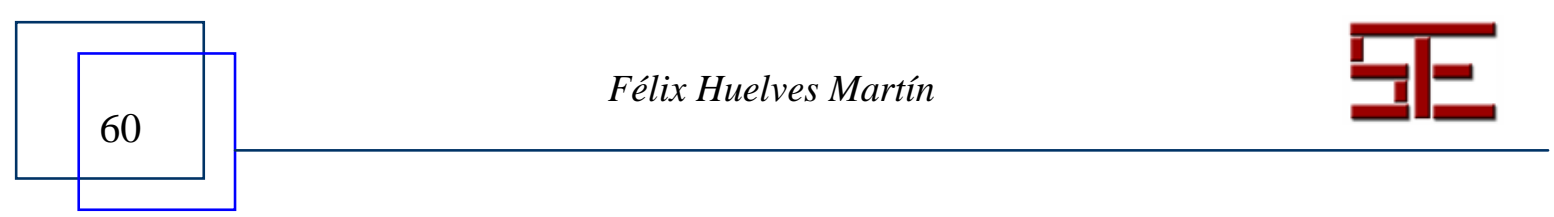




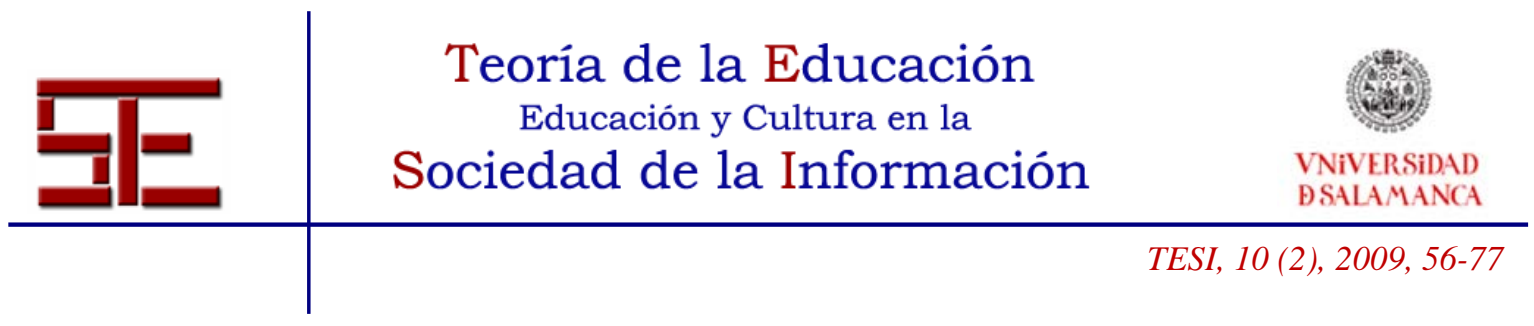

Estas posturas, principalmente sobre la correcta posición de mano sobre mesa y ratón, y mesa y teclado, facilitará en gran medida el avance del usuario/a, puesto que ya no bailará el puntero como "si estuviera vivo".

\section{3.- El Aprendizaje Digital en el Mayor}

Una nueva herramienta se pone en manos de una persona. Lo primero que piensa es en para qué sirve y cómo aprender a usarlo. Sea como sea, investigará, toqueteará y buscará la solución a sus problemas, puede que experimentando, puede que preguntando, o investigando en manuales y libros. Ahora la herramienta es un sistema computacional, que será la base para que dentro de muy poco experimente, se pregunte, investigue, y se comunique. Es imprescindible manejarse con estas herramientas para la vida cotidiana como lo fue en su tiempo el cambio al euro, el teléfono móvil, el uso del automóvil de varias marchas, etc.

Un entorno de posibilidades se abre ante la persona, sin embargo no son pocas las barreras que tiene que superar el adulto mayor para sentirse seguro en este medio, principalmente:

- El manejo de los periféricos básicos: ratón, teclado, pantalla, impresora...

- La virtualidad del nuevo entorno: sistemas operativos, sistema de almacenamiento por archivos y carpetas, etc.

- La relación entre ambos: órdenes. Input/Output.

Por ejemplo, el teclado puede resultar familiar al haber visto o utilizado máquinas de escribir de diferentes épocas y tipos, Sin embargo, el ratón es un elemento extraño, "novedoso", a pesar de ser, uno de los periféricos que menos ha evolucionado desde su invención. Es un nuevo concepto al que se tienen que enfrentar todos los usuarios, pero las personas mayores tienen especiales dificultades para manejarse con él y con sus posibilidades. Para solventar este asunto propondremos de forma rigurosa la obligación y repetición diaria de pautas ergonómicas, tanto para un mejor aprendizaje, como para evitar secuelas y lesiones innecesarias, y muy delicadas entre el alumnado mayor.

Actualmente, y bajo investigación-acción hemos podido constatar que los alumnos y alumnas que nunca han utilizado un dispositivo como el ratón (ya sea el modelo externo que sea: de bola, óptico, con o sin rueda de desplazamiento en el centro...) se

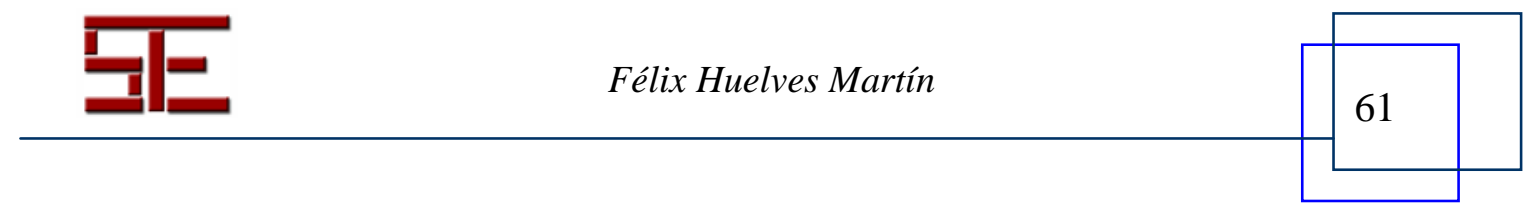




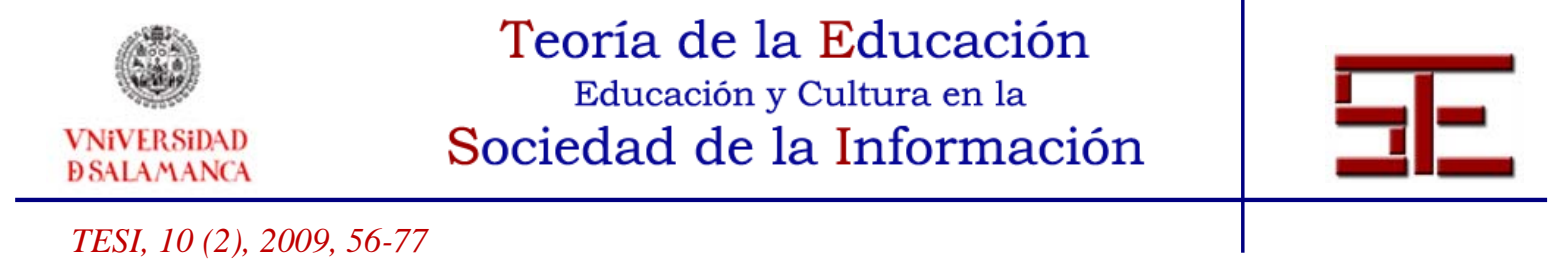

desenvuelven mejor con los ratones táctiles de ordenadores portátiles, gracias a la intuitividad de movimiento del par dedo-puntero que representan. No obstante, estos dispositivos aún están poco difundidos en los equipos de sobremesa, además de conservar la dualidad de botones habitual en este periférico. Más adelante hablaremos de estos conceptos, puesto que son los más complejos de manejar para el adulto recién iniciado.

Aprender nuevos conceptos y destrezas, nuevas posturas y prácticas, requiere esfuerzo y dedicación. La frustración, suele ser uno de los elementos más comunes en la alfabetización informática de personas adultas. Hemos de demostrar paciencia y comprensión, así el alumnado se sentirá apoyado, y crearemos un clima de confianza que facilitará el aprendizaje al ritmo de cada uno.

\section{2.- CONTEXTO Y PERFIL ALUMNOS}

Esta buena práctica, se desarrolla en un aula con 8 equipos informáticos, de los cuales uno es el para el uso del docente, y los otros 7 para el alumnado. La organización y puesta en marcha de esta iniciativa corría a cargo de otra entidad, la cual nos facilitó el listado de alumnos que tendríamos por sesión: concretamente 14 alumnos, por lo que tenemos que sentar a dos personas juntas por equipo. Como ya hemos dejado caer en la introducción, esto no es por sí mismo ningún problema, sino incluso puede llegar a ser todo lo contrario, una gran oportunidad para un aprendizaje más efectivo.

Las sesiones de alfabetización digital están repartidas en 2 horas, 2 días a la semana... Esto es, 32 horas mensuales de clase, con un total de 64 horas por taller. El alumnado tenía un perfil muy similar, al ser un taller de iniciación a la informática, se da poca variación con respecto al uso del ordenador, el manejo del ratón, y la ejercitación en el teclado y las herramientas de software básicas. Sin embargo, existe un detalle que hemos de tener en cuenta siempre, y que en este caso también se dio: la posibilidad del alumnado de seguir o no practicando fuera del aula, sea con su propio equipo, prestado por sus hijos/as, nietos, centros públicos o privados de acceso a Internet, etc.

\section{3.- OBJETIVOS}

Hasta aquí la rigidez de los convenios pautados por la entidad para un taller de informática para mayores. Ahora, la oportunidad del profesorado de organizar las

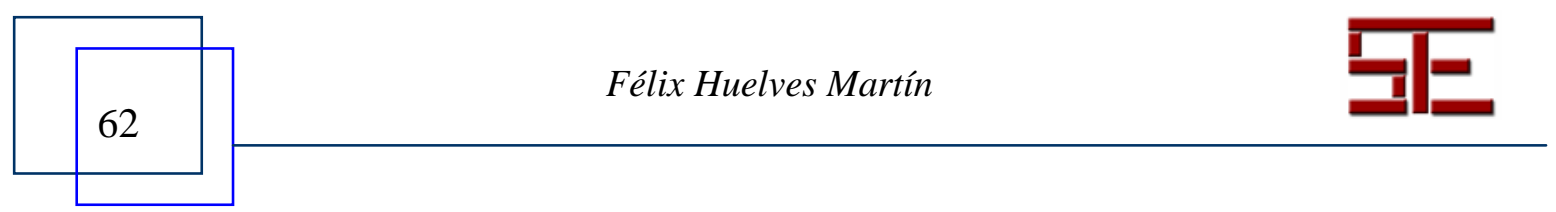




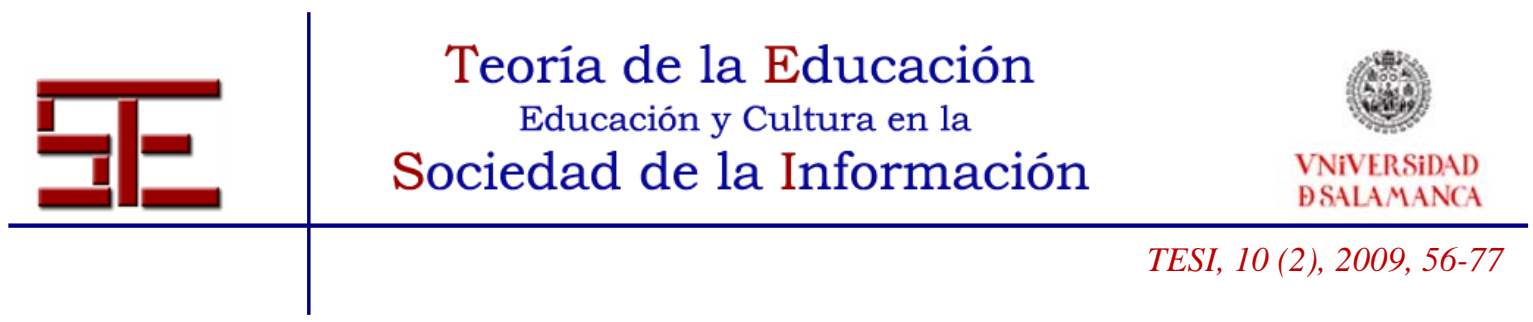

sesiones en función de unos objetivos para el desarrollo de destrezas y capacidades claras:

- Desarrollar las destrezas viso-motoras básicas de los soportes informáticos actuales mediante la ejercitación de prácticas variadas con los periféricos habituales: ratón, teclado y pantalla.

- Identificar y comprender los nuevos conceptos de software informáticos a los que se enfrentan (ventana, puntero, cursor, programa, aplicación, barras de navegación/ tareas/herramientas/menú...) relacionándolos con los conceptos y conocimientos previos que el alumnado ya posee en su experiencia vital.

- Agrupar y clasificar los elementos básicos (fichero/archivo, carpeta, subcarpeta, discos duros, discos extraíbles...) mediante la relación con el contexto experiencial y particular del alumnado y la ejercitación de diferentes acciones entre estos elementos.

Estos objetivos no sólo tienen como meta la ya conocida alfabetización digital, sino además añadir valor a cada aprendizaje, enseñando a los alumnos a aprender por sí mismos de tal forma que podamos evitar la brecha digital, que no sólo separa a países o personas con mayor o menor capital económico, sino que supone un distanciamiento intergeneracional cultural y de accesibilidad ante los evidentes cambios en la sociedad y las instituciones. Póngase de ejemplo, y por mencionar algunas de las que más quebraderos de cabeza están dando a nuestros mayores: la cita previa para el dni-e, el pasaporte, la vida laboral por Internet, etc.

Junto a estas competencias a desarrollar, cabe añadir otras más que el profesor ha de tener en cuenta en el desarrollo diario de sus clases, a saber:

- Potenciación del respeto ante el ritmo de aprendizaje del compañero mediante la realización conjunta de ejercicios en parejas.

- Desarrollar y mejorar los hábitos de constancia y compromiso, mediante técnicas de refuerzo positivo, lenguaje autodirigido, y clima de compañerismo y apoyo.

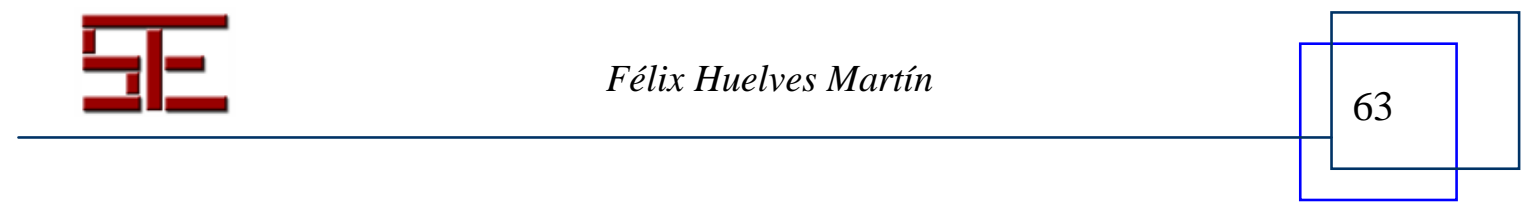




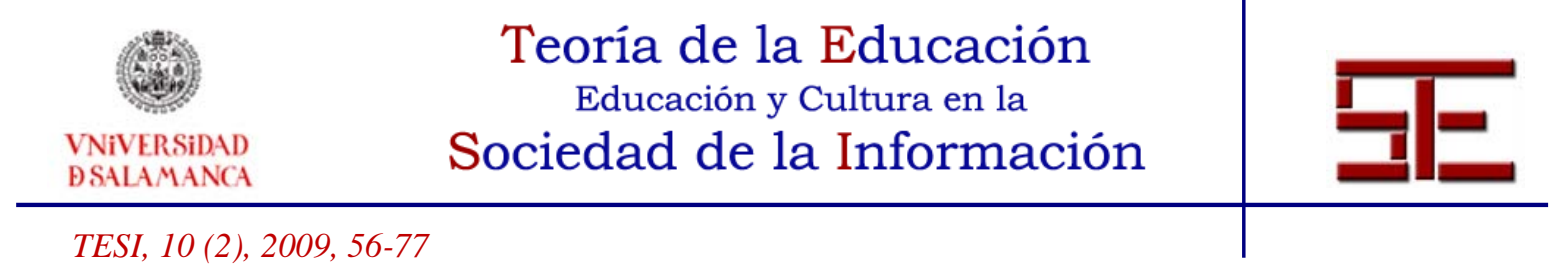

- Aumentar el umbral de tolerancia a la frustración, mediante la paciencia del profesorado, la comprensión de los compañeros, y el desarrollo de las actividades según el ritmo individualizado del alumno/a.

Se podría realizar una lista aún más larga de competencias a desarrollar según niveles, conocimientos, punto de partida, y tiempo del taller. Sin embargo, con estos dos tríos de destrezas y actitudes, podemos crear unas bases sobre la que asentar posteriormente cualquier otro objetivo que se necesite implementar en un taller de informática con adultos.

Sin embargo no queremos dejar pasar la oportunidad de recordar las características del alumnado, que como personas mayores que son, hemos de tener en cuenta, y usar estratégicas y técnicas adecuadas a sus necesidades:

\section{1.- Frente al Olvido:}

“-Atención: Se centra la atención exclusivamente en lo que se está haciendo.

-Verbalización: Se repite en voz alta lo que se está haciendo, por ejemplo "Estoy cerrando la llave del gas"

-Visualización-asociación: Se visualiza la escena, incluso la ropa que se lleva puesta, los objetos de alrededor... y se asocia la acción a estas imágenes para recordarlo después ("Puedo estar en la calle y pensar si he cerrado la llave o no"):

- Repensar: Se trata de traer a la memoria la escena, "cómo iba vestido (para saber si se trata de hoy o de otro día), si lo he repetido en voz alta..."

- En algunos olvidos: Volver al último lugar: Por ejemplo, "En último caso repito las acciones que estaba realizando cuando tuve en mis manos las llaves por última vez"

(Montorio Cerrato, I. \& Perez Rojo, G, 2006, p.19).

Teniendo en cuenta estos consejos, y apoyándonos en nuestra metodología en espiral, recreamos un sistema de aprendizaje progresivo, reactivando la memoria del alumnado: Atención: centrada en la tarea, por ejemplo, en las nuevas destrezas oculo-motrices: ratón-puntero.

- Verbalización: el profesorado dice en voz alta cada paso como si fuera un usuario, dirigiéndose al alumnado en primera persona. Luego, los alumnos se repiten dichos pasos mientras realizan los ejercicios paso a paso, y si es necesario, se realizarán los

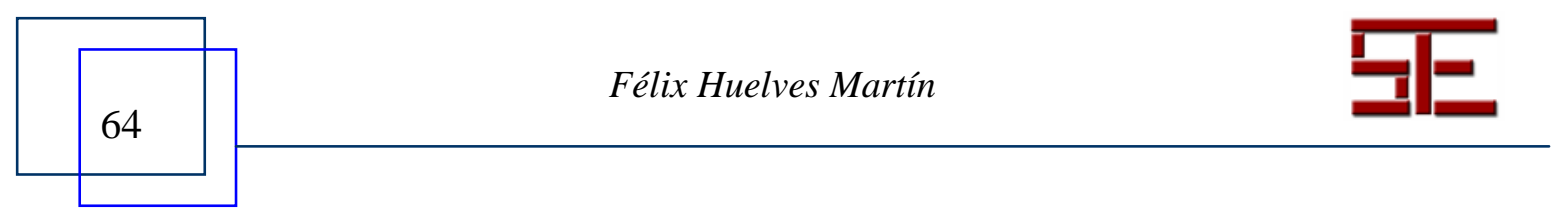




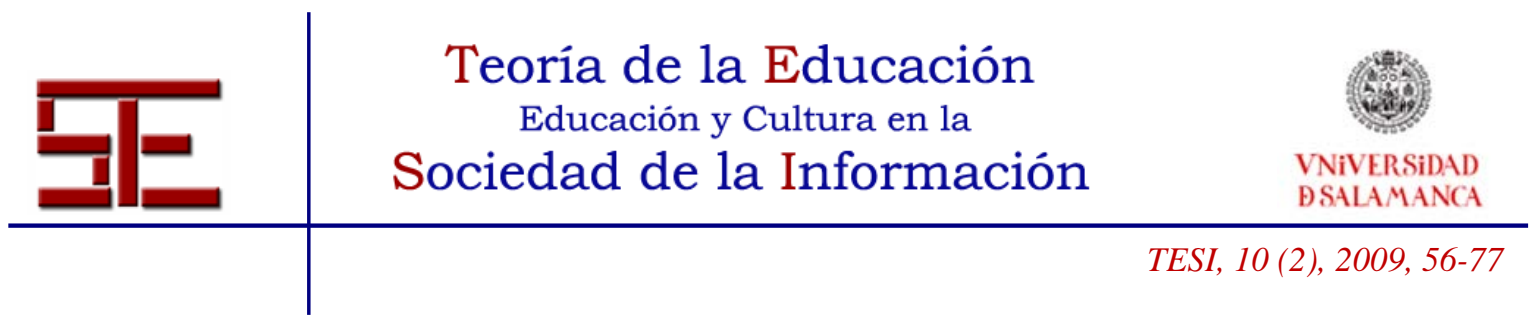

ejercicios juntos una tercera vez, ya sea en grupo, ya sea por parejas, o individualmente en aquellos casos en los que se requiera.

- Repensar: traer a la memoria la escena, elementos que activen la recuperación de la memoria, enlazando la cadena de pensamientos. La camisa que llevaba el día anterior, retomar la lección anterior en voz alta al principio de clase, a ser posible por un alumno/a.

- Visualizar: Antes de realizar el alumno ejercicios de repaso o profundización (según dónde se encuentre), visualizará:

o El objetivo

o Los pasos para conseguir el objetivo

o Verbalizará estos pasos

o Realizará la acción

\section{2.- Para la motivación:}

- Motivación Interna, que dirigido a la preparación mental de una acción determinada, para animarnos (a nosotros mismos) a emprender la tarea "con interés", o dicho en otros términos, con esa energía interior ya mencionada que nos empuja a lograr nuestros objetivos sin necesidad de una coerción exterior.

- Motivación Externa, dirigida a animar a los demás a ejecutar esa misma acción con interés, es decir, de un acto de comunicación por el cual una persona infunde a otras la motivación para hacerla.

Contamos con ambas para crear el clima de cooperación en la clase, y bajo diferentes metodologías de interacción formador/a-alumnado, e interalumnos/as, podremos mejorar la motivación en caso de que descienda. Inicialmente contamos con una alta motivación, se han apuntado de forma voluntaria. Sin embargo esta suele descender por culpa del siguiente factor que hemos de equilibrar y mantener vigilado.

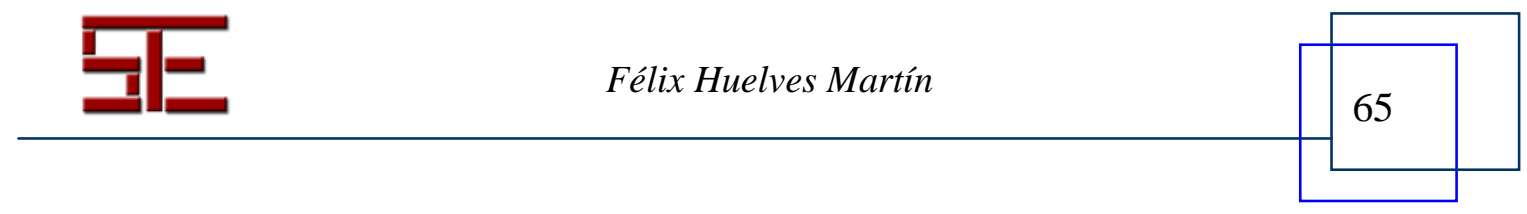




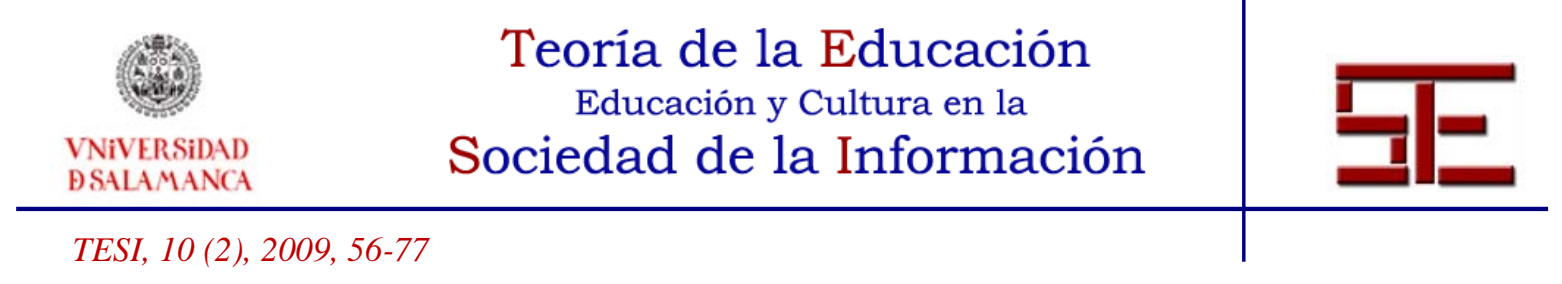

\section{3.- Frente a la Frustración}

Ante la sensación de incapacidad, el adulto tiende a sentirse inútil, o demasiado viejo para aprender, e incluso bloqueado. Es necesario utilizar técnicas de aumento de la motivación, basadas en la evidencia:

a. Estas aquí voluntariamente, porque te interesa aprender cosas nuevas.

b. Es cuestión de ritmo y constancia, no todos aprendemos al mismo ritmo, depende de numerosos factores, como la experiencia previa y el conocimiento sobre el tema en cuestión.

\section{4.- CONTENIDOS}

Los contenidos en un taller de alfabetización digital, no han de confundirse con los objetivos. Si nuestro objetivo es desarrollar la destreza del uso del ratón, el contenido no puede ser simplemente explicar los conceptos: "botón derecho, botón izquierdo, y movimientos básicos”. En este caso no cumpliríamos los objetivos, sino que estaríamos disertando sobre unos conceptos que el alumno no conoce, y que tampoco asimilará fácilmente.

El contenido es la escusa perfecta para el desarrollo de los objetivos, tanto de capacidades como de valores, a través de destrezas y habilidades en el manejo de los periféricos, el software específico y las actitudes de compañerismo, apoyo, tolerancia a la frustración, paciencia, etc.

El contenido a trabajar, por supuesto, contendrá los conceptos básicos de:

Almacenamiento:

- Dispositivos internos: disco duro.

- Dispositivos externos: cd-rom, dvd-rom, memorias flash, usb-pendrive, tarjetas $\mathrm{sd} / \mathrm{xd}$...

- Periféricos de lectura de dispositivos: lector/grabador de cd/dvd

- Puertos de lectura/escritura: usb.

Ratón:

- Botón izquierdo. Funciones: Ejecución y apertura de elementos.

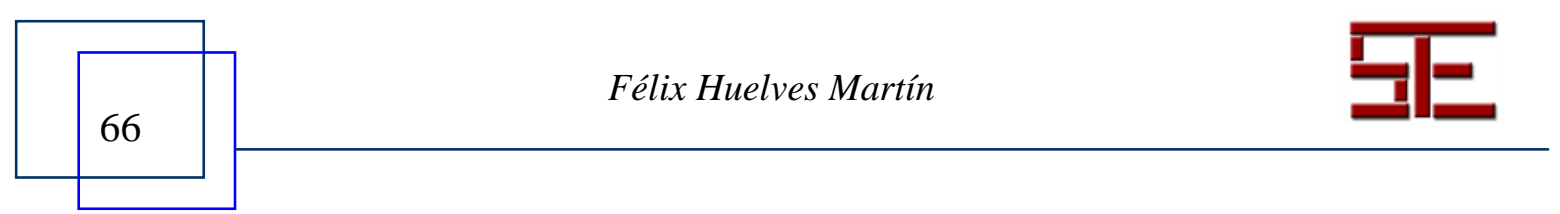




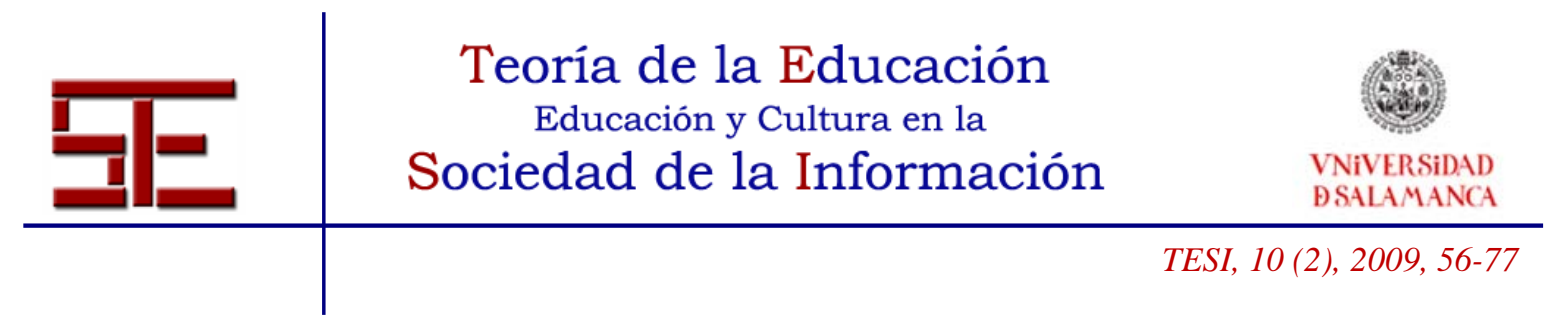

- Botón derecho. Funciones: Despliegue de menús de opciones, diversas ejecuciones sobre esos elementos.

Teclado:

- Posición de las letras.

- Caracteres especiales

- Combinación de teclas especiales: Ctrl, Shift, Tab, Alt Gr, F1...F12. etc.

Entorno: Sistema Operativo.

- Ventana. Botones de cierre, minimizar/maximizar, restaurar.

- Carpeta. Subcarpeta. Fichero.

- Programa.

- Icono. Acceso directo.

- Copiar/Cortar/Pegar

Estos elementos son la base de la informática actual, y muchas veces los pasamos demasiado rápido en las clases con adultos, o creemos que lo aprenden igual que un joven acostumbrado a este tipo de entornos, capaces de aprender a manejar un nuevo dispositivo digital sin leer el manual de instrucciones. Sin embargo, nuestros mayores, requieren de una alfabetización, y esto significa, un aprendizaje nuevo, construyendo cada peldaño, basándonos en su experiencia. Por lo que es fundamental trabajar lentamente estos conceptos, mediante otros contenidos más lúdicos, interesantes, y útiles, que puedan motivar y servir de nexo de unión entre conocimientos previos (de la vida) y conocimientos digitales modernos.

\section{Según la UNESCO (2004):}

"Bruner identificó tres principios que sirven de guía para el desarrollo de la instrucción:

(1) la instrucción debe estar relacionada con las experiencias y los contextos que hacen que el alumno esté deseoso y sea capaz de aprender (disposición); (2) la instrucción debe estar estructurada de modo que el alumno pueda aprehenderla fácilmente (organización espiral); (3) la instrucción debe estar diseñada para facilitar la extrapolación y/o para completar las brechas de conocimiento (llegando más allá de la información dada)” (p.32)

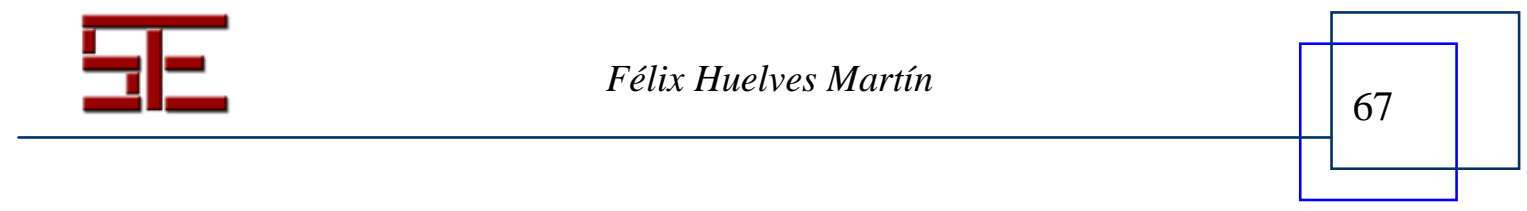




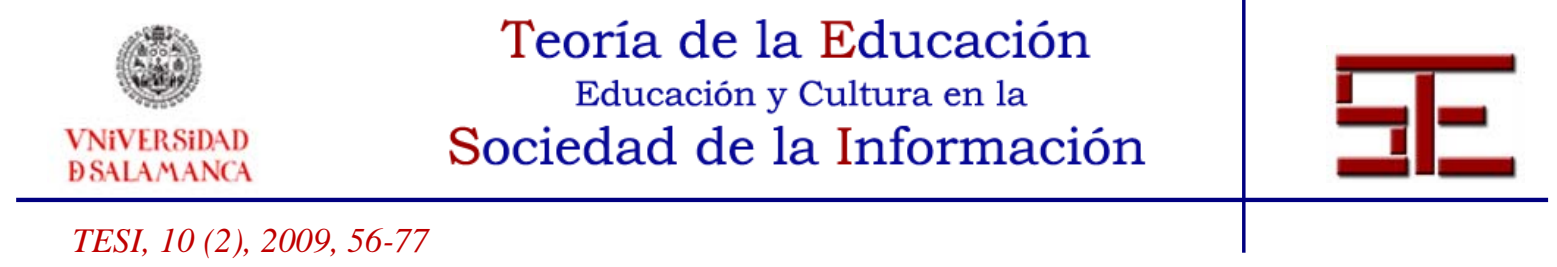

\section{5.- METODOLOGÍA}

Es evidente que las personas mayores, tienen mucho recorrido personal anterior y muy diferente entre sí, por lo que el individualismo suele ser el primer obstáculo que hemos de vencer. A veces es necesario recordarse que las personas somos seres sociales, y que por lo tanto, necesitamos de los demás para seguir creciendo y aprendiendo.

Es imperativo para nosotros, los docentes, tener claro que el aprendizaje se adquieren gracias a la interacción con el medio, dentro del cual, estamos las demás personas que enriquecemos las experiencias de unos y de otros, otorgando un valor añadido a cualquier información empaquetada en un tutorial, manual, o libro de software. Esta tarea, de concienciación corresponde, en primer lugar, a los docentes y formadores de adultos y mayores. Una vez superada esta barrera hemos de transmitir a nuestro alumnado que el aprendizaje permanente es una responsabilidad de cada persona consigo misma y con su compañero. Para ello, la metodología ha de ser coherente con los fines que buscamos.

Proponemos, en este caso, un taller basado tanto en la experiencia del alumnado, que puede no ser necesariamente relacionada con la informática; así como en la construcción progresiva del conocimiento teniendo en cuenta los siguientes factores:

- Organizadores previos. Cada sesión, ha de tener:

o Un breve repaso de la sesión anterior, activando así los esquemas mentales del alumnado, preparándolo para la clase del día.

o Un resumen globalizador de lo trabajado en el día.

- Conocimientos y experiencias previas. Es necesario que se active en el alumno y la alumna el recuerdo. El nuevo conocimiento sólo se construye sobre los pilares que cada persona posea, y estos son su propia vida, sus aprendizajes anteriores. Realizar símiles al contexto, reactivar el recuerdo mediante preguntas como ¿Os acordáis cuando...? Y de esta forma se enlaza el nuevo concepto con el anterior en la mente de los alumnos, facilitando así su comprensión y retención.

Veamos, como ejemplo, pares de elementos que utilizados a forma de símil en el taller de alfabetización digital de adultos facilitan la activación, explicación, relación y

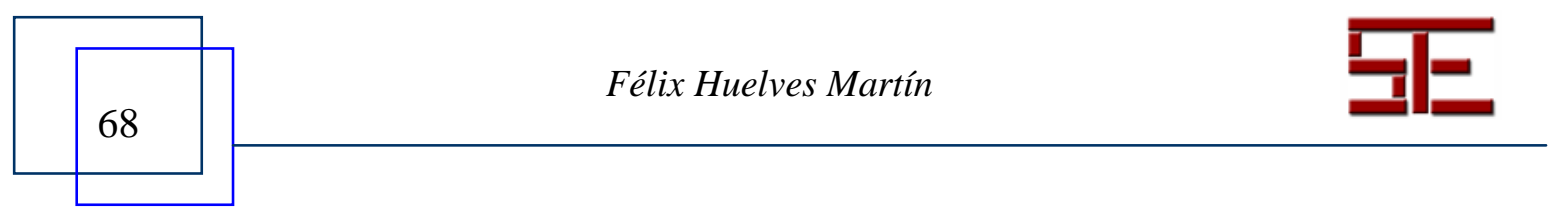




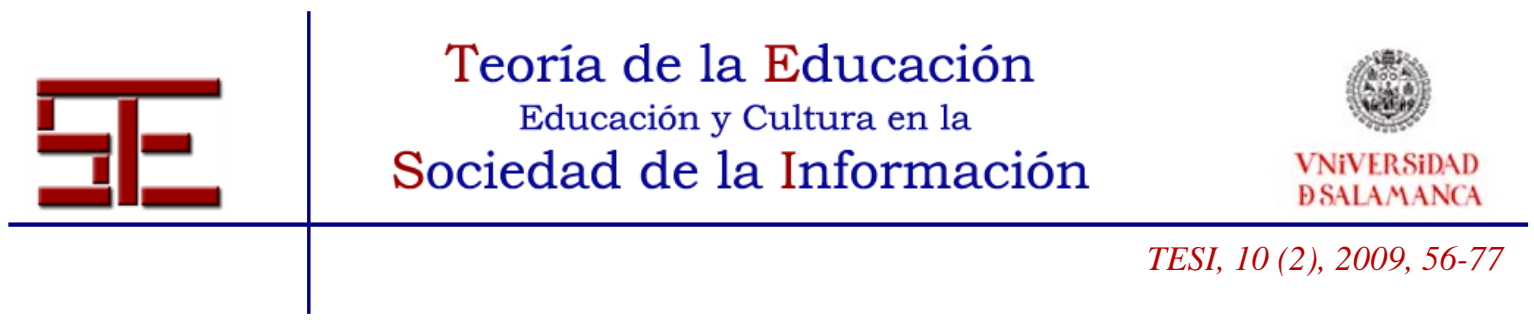

construcción de esquemas mentales entre los conocimientos que ya trae el alumnado y el nuevo que queremos enseñar:

- Puertos de lectura/escritura: usb.- enchufe: macho/hembra, sólo una posición es la correcta, si forzamos, rompemos el dispositivo.

- Ventana. Botones de cierre, minimizar/maximizar, restaurar.

- Carpeta. Subcarpeta. Fichero: Con una simple caja, una carpeta o archivador, plásticos de archivo, y folios el concepto suele ser más claro que el símil clásico del árbol, aunque también puede ser útil: Tronco, ramificaciones, hojas. Símil de las muñecas rusas.

- Cortar-Pegar: Piaget tendría mucho que decir al respecto. Un niño/a de cierta edad no es consciente de la desaparición, por ejemplo, de la muñeca rusa en el interior de otra. Este es nuestro corta y pega. Un concepto de traslado difícil de explicar muchas veces. El mejor ejemplo: la realidad de un taller de manualidades auténtico, un collage con revistas y periódicos. Cortar con las tijeras, pegar,

etc. Estos elementos servirán de base para futuros conceptos de selección simple, múltiple, selección de texto, de imágenes en retoque fotográfico, etc.

Como advirtió Vygotsky (1978) los alumnos aprenden mejor en colaboración con sus pares y demás personas cuando se involucran de forma activa en tareas interesantes.

De esta forma, manejaremos técnicas colaborativas que permitan una adquisición eficaz de competencias, capacidades y valores oportunos ante la constante evolución y actualización de hardware y software.

De entre estas técnicas hemos puesto en práctica:

- La tutoría de pares, entre compañeros, en caso de que alguien faltase a alguna sesión anterior: al estar sentados dos personas por equipo, esta técnica resulta muy eficaz para poner al día en pocos minutos al compañero, antes de empeza con los nuevos conceptos, ejemplos y ejercicios.

- El método de Mastery Learning adaptado: mediante la programación de unidades de secuenciación grupal e individual, de tal forma que si una pareja o individuo avanza, y su pareja se retrasa o alguien del grupo va más retrasado tenemos dos alternativas:

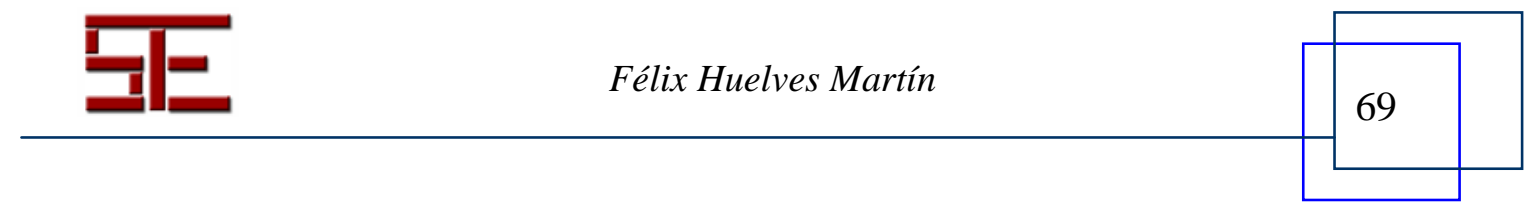




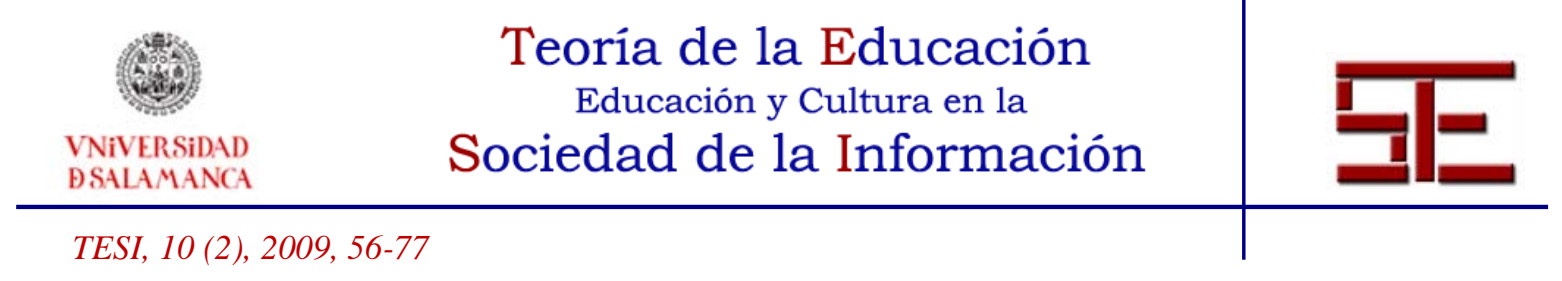

o Unidades de refuerzo, atención individualizada, y mayor ejercitación, o incluso aplicando la ya mencionada técnica de pares.

o Unidades de profundización, con las que puede avanzar en el conocimiento de los mismos conceptos (no de otros diferentes) pero con un mayor nivel de comprensión y dificultad de resolución

- Adaptive Learning Enviorements Model “ALEM”, este método, validado por Margaret Wang, permite crear entornos de aprendizaje para que los estudiantes puedan adquirir destrezas básicas y a la vez aumenten la confianza en su capacidad para aprender y hacer frente a las demandas sociales y físicas del entorno, mediante:

o Estructuración alta del aprendizaje.

o Aprendizaje basado en el conocimiento.

- El roleplaying, en el cual, cada alumno y alumna, de manera voluntaria, comenzaría la clase asumiendo el papel del profesor, y durante los primeros 5 minutos, recapitula los contenidos, destrezas y aprendizajes de la sesión anterior.

- La resolución de problemas, principalmente de física y geometría mediante diversos juegos para la ejercitación tanto del calculo mental, la intuición así como la práctica viso-motora y el compañerismo.

Recordando a un profesor de la facultad de Pedagogía, nos dijo un día, rígido, erguido, con una postura señorial: "no hay cosa más seria que el humor”, y así es; estas técnicas pueden parecer unas más "educativas” y otras "lúdicas”, pero no dicha distinción resultaría falsa, son más bien todas y cada una de ellas seria y llanamente técnicas efectivas de aprendizaje.

No olvidemos que estas técnicas requieren de una planificación, la creación del clima adecuado de forma progresiva y el cambio de paradigma en el rol docente/alumnado. (Véase tabla 1.1: Unesco.2004.p.27) Por lo tanto, a continuación explicitamos la metodología a seguir para todo el taller, y para cada sesión, intentando dejar en los esquemas mentales del lector un mapa sencillo que puede ayudar a organizar la formación, en este caso, de las TIC.

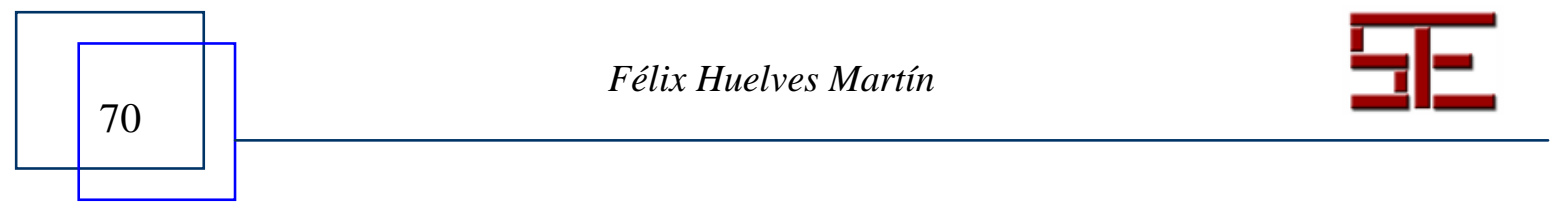




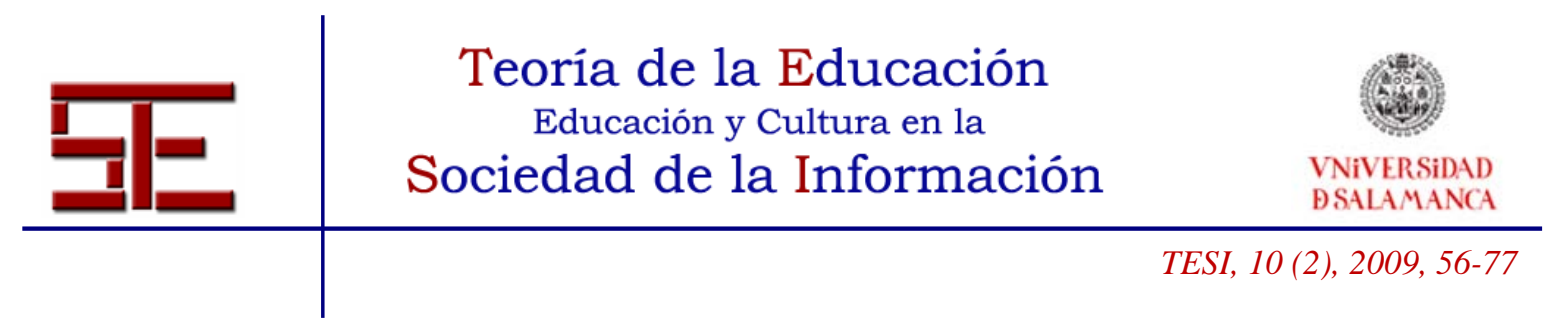

Tabla 1.1 Entorno de aprendizaje centrado en el docente y centrado en el alumno

\begin{tabular}{|c|c|c|}
\hline & $\begin{array}{l}\text { Entorno de Aprendizaje } \\
\text { Centrado en el Docente }\end{array}$ & $\begin{array}{l}\text { Entorno de Aprendizaje } \\
\text { Centrado en el Alumno }\end{array}$ \\
\hline Actividades de clase & $\begin{array}{l}\text { Centradas en el docente. } \\
\text { Didácticas }\end{array}$ & $\begin{array}{l}\text { Centradas en el alumno. } \\
\text { Interactivas }\end{array}$ \\
\hline Rol del profesor & $\begin{array}{l}\text { Comunicador de hechos. } \\
\text { Siempre experto. }\end{array}$ & $\begin{array}{l}\text { Colaborador. A veces aprende } \\
\text { de sus alumnos. }\end{array}$ \\
\hline $\begin{array}{l}\text { Énfasis } \\
\text { instruccional }\end{array}$ & Memorización de hechos & $\begin{array}{l}\text { Relacionar, cuestionar e } \\
\text { inventar }\end{array}$ \\
\hline $\begin{array}{l}\text { Concepto de } \\
\text { conocimiento }\end{array}$ & $\begin{array}{l}\text { Acumulación de hechos. } \\
\text { Cantidad }\end{array}$ & Transformación de hechos \\
\hline $\begin{array}{l}\text { Demostración de } \\
\text { aprendizaje efectivo }\end{array}$ & $\begin{array}{l}\text { Seguir las normas como refe- } \\
\text { rencia }\end{array}$ & $\begin{array}{l}\text { Nivel de comprensión del } \\
\text { alumno }\end{array}$ \\
\hline Evaluación & Múltiple opción & $\begin{array}{l}\text { Pruebas con criterio de refe- } \\
\text { rencia. Carpetas de trabajo y } \\
\text { desempeño. }\end{array}$ \\
\hline Uso de Tecnología & Repetición y práctica & $\begin{array}{l}\text { Comunicación, acceso, colabo- } \\
\text { ración y expresión. }\end{array}$ \\
\hline
\end{tabular}

\section{1.- Planificación por Sesión:}

Para comenzar una sesión de informática con personas mayores, es muy importante aplicar siempre las pautas ergonómicas recomendadas. Así iniciaremos el día con un recordatorio ergonómico, estiramiento y calentamiento. Durante la sesión el profesorado estará atento a posibles percances y corregirá la postura para un adecuado uso y disfrute de la sesión.

En primer lugar realizaremos una breve presentación de lo que vamos a hacer el día de hoy, los objetivos principales que vamos a conseguir, la metodología que vamos a aplicar y cómo estos contenidos conectan con sesiones anteriores. Si es necesario también se realizará durante la sesión, de forma individualizada y en voz alta si es necesario para que todo el grupo lo realice.

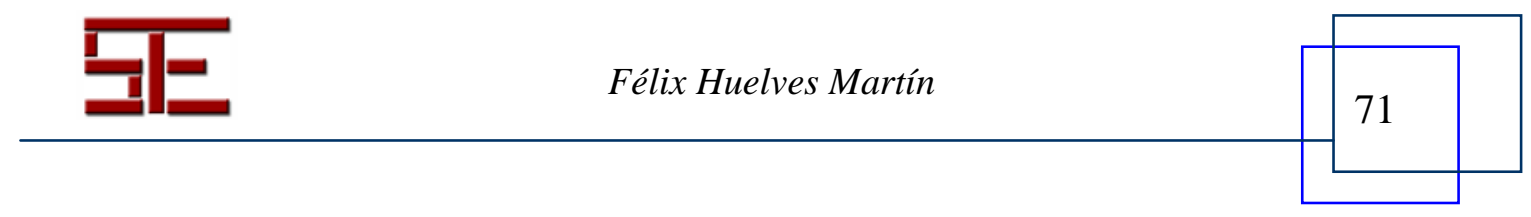




\begin{tabular}{cc}
$\begin{array}{c}\text { Teoria de la Educación } \\
\text { Educación y Cultura en la } \\
\text { VNiVERSIDAD } \\
\text { BSALAMANCA }\end{array}$ & Sociedad de la Información \\
\hline TESI, 10 (2), 2009, 56-77 &
\end{tabular}

En segundo lugar, es muy importante tomar el tiempo necesario, realizaremos el repaso para la activación de los conocimientos previos, el recordatorio de las sesiones del día anterior, y la participación del alumnado en esta experiencia.

A continuación comienza la sesión de unidades de contenidos diaria, mediante una breve explicación a modo de organizador previo, explicación básica de conceptos, y puesta en práctica a través de experiencias y ejercicios por nivel, por parejas, intercambio de elementos periféricos (estilo dinámica), y resolución individual ( o grupal) de dudas.

La metodología a seguir en este punto es: Primero yo, luego juntos, y luego cada uno, para que el profesor pueda ir viendo la progresión del alumnado y así adaptar la sesión según el ritmo grupal e individual, tomando medidas de refuerzo o profundización según sea conveniente.

La última fase de la sesión es el repaso de los conceptos, a modo de esquema visual, que permita crear en el alumnado un mapa mental de relaciones entre los contenidos del día anterior, los de hoy, y los de su propia experiencia. ( véase fig.1.)

\section{Ergonomía. Estiramiento. Calentamiento}

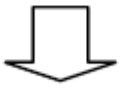

\section{Presentación de los objetivos del día.}

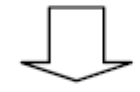

Repaso de la sesión anterior. Conexión con los objetivos actuales

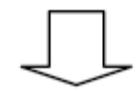




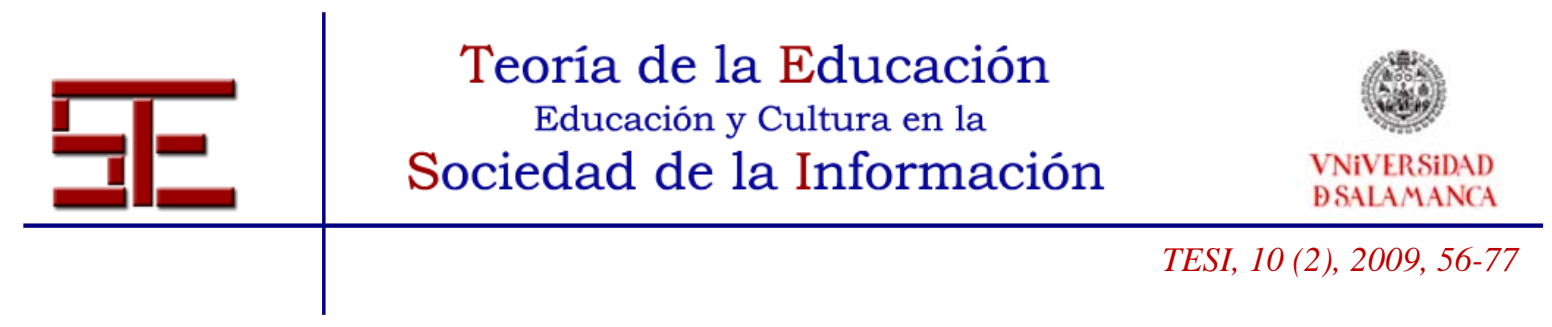

\section{Org.previos. Sesión actual. Ejercitación.}

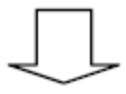

\section{Reconceptualizando. Esquema visual. Repaso}

fig.1. Sesión diaria

\section{2.- Planificación global del taller:}

La Planificación de todas las horas del taller tiene en cuenta las unidades de contenidos, refuerzo y profundización (véase fig.2), así como la metodología constructiva helicoidal, siendo las primeras sesiones más estructuradas con mayor protagonismo del profesor/a, para ir pasando progresivamente a la autonomía de los alumnos y alumnas, la ayuda en pares, y la atención personalizada para cada asistente. (véase fig.3)

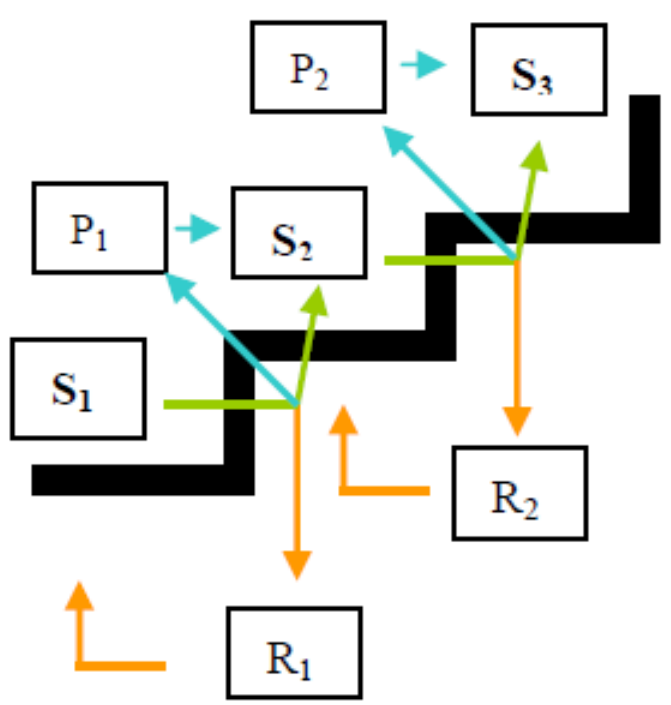

fig.2. Aprendizaje escalonado con feedback. Sx sesiones, $R_{x}$, repaso. Px, profundización.

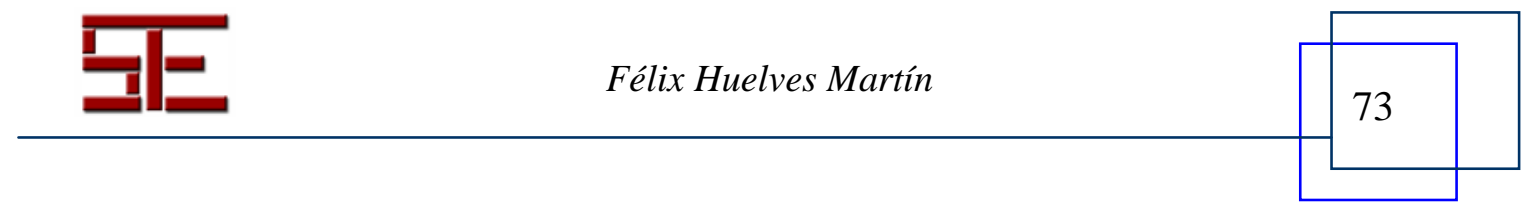




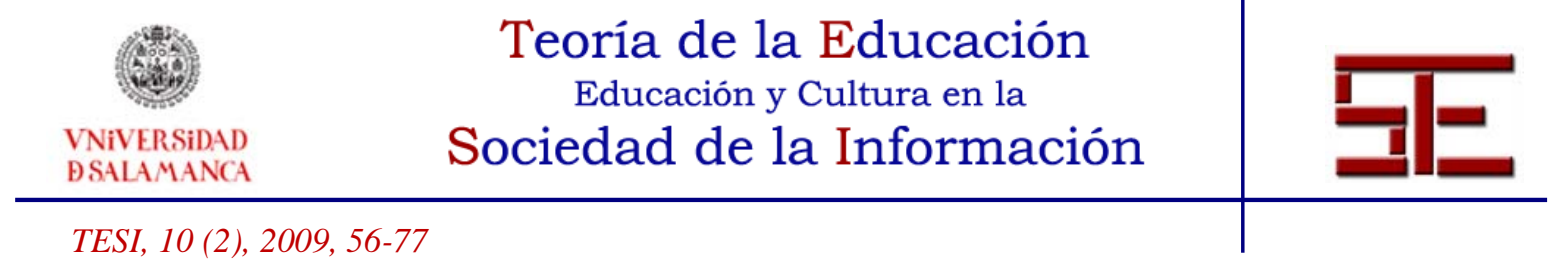

De esta forma, el taller completo se concibe como un sistema de aprendizaje constructivo, paso a paso, en forma espiral, reactivando, repasando los conocimientos de cada día al inicio de la sesión, y ejercitando lo ya "impartido" junto con un nuevo grado de dificultad, aumentando las destrezas y actitudes del alumnado de forma progresiva.

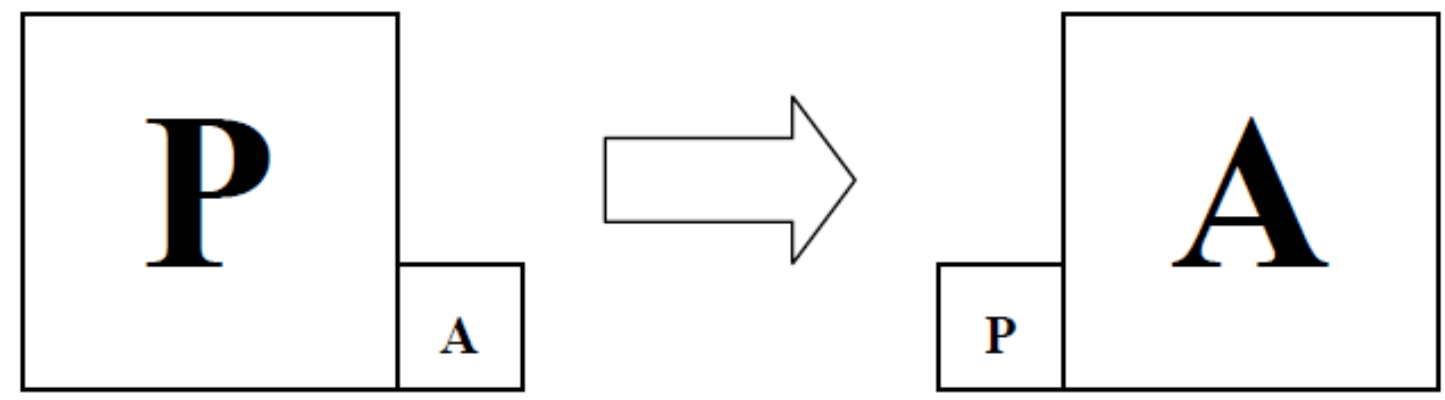

fig.3. Rol metodológico. P: actuación profesorado. A: actuación del alumnado.

\section{6.-CASOS DE ÉXITO}

\section{1.- Frustración y bloqueo.}

Como ejemplo, ante la evidente frustración de una alumna por su aparente lentitud al aprender, el profesor de informática, pedagogo de carrera le preguntó: - ¿Entendiste el concepto que se trataba?-, a lo que el alumno contestó: -sí, pero no me sale, soy incapaz de aprender estas cosas nuevas, los jóvenes podéis, pero nosotros ya no-. El profesor, de mediana edad, curioseó:- ¿a qué te has dedicado profesionalmente?-; a lo que la alumna, cambiando "el chip”, más animada y dejando a un lado, por un momento lo que la distraía (una nube oscura de pesimismo), contestó: -He sido costurera durante 40 años [...]- y así, la alumna mientras iba contando un poco su experiencia profesional se iba olvidando de lo que la estaba "bloqueando". Unos minutos más tarde, aprovechando que la alumna estaba un poco más animada, el profesor puntualizó: -A mi me costaría horrores, meses y sudores aprender a hacer ganchillo, nunca he cogido una aguja- Frase que, con una carcajada general de toda la clase, cambió el clima y con la cual, ella, mirando a sus compañeros, sonrió y volvió a tomar entre sus manos el ratón.

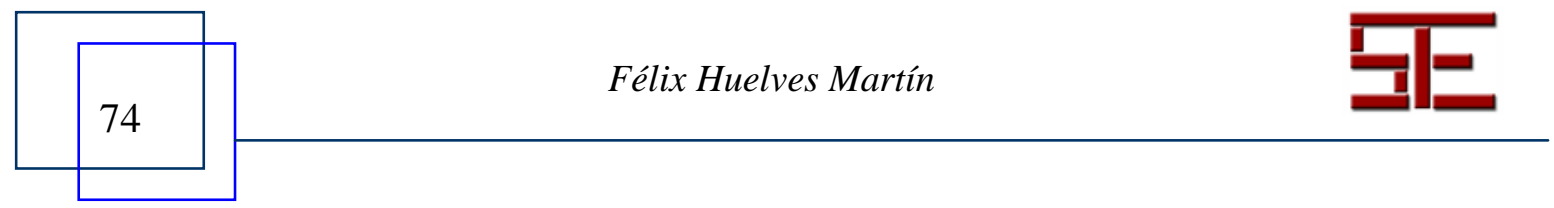




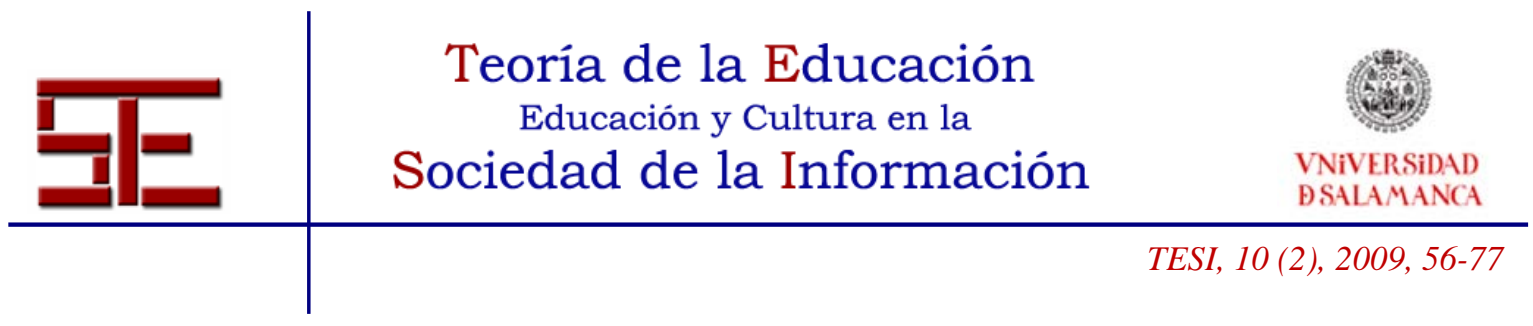

\subsection{Conceptos de Fichero.}

Para explicar el concepto de Carpeta, subcarpeta y Fichero, se utilizó la puesta en práctica de teatro por parte de las parejas, de tal forma que con unos simples folios, unas carpetillas transparentes, un archivador por pareja, y una cajita o la estantería de la sala, pudiéramos escenificar corporalmente el escalonamiento de estos conceptos (y de esta forma facilitar la memorización, retención y futura recuperación).

\subsection{Ejercitando el manejo del ratón de forma lúdica.}

Usar el ratón pinchando de un lado a otro de la pantalla de fondo de escritorio, o abriendo y cerrando ventanas, suele cansar al poco rato. La mejor manera es utilizar algún sistema lúdico para la ocasión. En este caso, utilizamos varios juegos gratuitos online en los que el usuario necesita ejercitar diferentes opciones del ratón (pinchar con el botón izquierdo, arrastrar, y movimiento ratón-puntero) para resolver enigmas de física mecánica: cuerpos que caen o descuelgan, pelotas que chocan entre sí, etc. A modo de anécdota, comentar lo mucho que sonrieron, el buen clima que generaba cada vez que utilizábamos este sistema a mitad de clase a modo de descanso, o al finalizar a modo de recompensa y estimulo para la ejercitación.

\section{7.- A MODO DE CONCLUSIÓN.}

La experiencia fue todo un éxito, la mayor parte de los alumnos y alumnas quiso apuntarse al siguiente nivel de iniciación a la informática, así como la mejora de las habilidades y colaboración entre ellos, notablemente diferente con respecto al principio de las sesiones. Con una metodología sencilla y coherente el alumnado disfruta junto al profesor durante todo el proceso de aprendizaje.

Con respecto al docente, comentar que no hay mayor alegría que el llamado "suicido del profesorado", cuando éste ya no es necesitado por los alumnos y alumnas sino que, por el contrario son autónomos en su aprendizaje (de un sistema estructurado se pasa progresivamente a un sistema de autogestión e investigación). Incluso, después de este tiempo, algunos se han convertido en docente de nuevos alumnos/as.

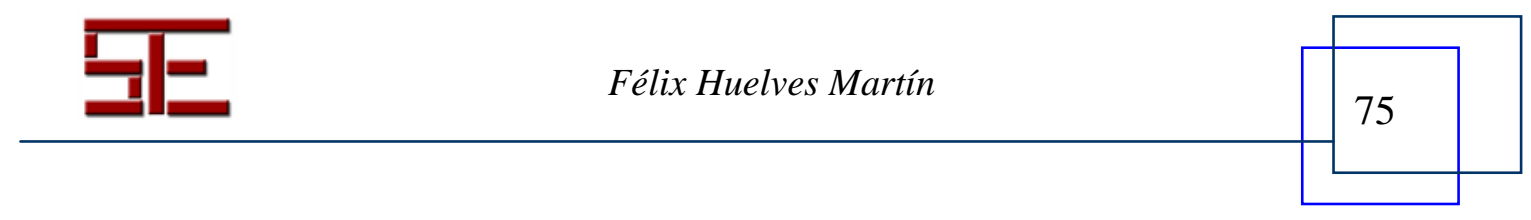




\section{REFERENCIAS BIBLIOGRÁFICAS.}

Instituto Nacional de Seguridad e Higiene el Trabajo NTP 602: El diseño ergonómico del puesto de trabajo con pantallas de visualización: el equipo de trabajo. Ministerio de $\begin{array}{lllll}\text { Trabajo } & \mathrm{y} \text { Asuntos Sociales: EN }\end{array}$ http://www.insht.es/InshtWeb/Contenidos/Documentacion/FichasTecnicas/NTP/Fichero s/601a700/ntp_602.pdf.

Montorio Cerrato, I. \& Pérez Rojo, G. (2006). Memoria Cotidiana en los mayores En Lecciones de Gerontología en Informes portal Mayores, 60. En http://www.inmsersomayores.csic.es.

Servicio de Prevención de Riesgos Laborales (2008). Ergonomía de la Oficina. Universidad de Jaén: España http://www.ujaen.es/serv/serobras/SPRL/ERGONOMIA/ERGONOMIA/ergonomia\%2 0de\%20la\%20oficina.pdf.

UNESCO (2004). Las tecnologías de la información y la comunicación en la formación docente. Guía de planificación. Montevideo: Uruguay.

Vega, J.L, Bueno, B \& Buz, J. (1999). Desarrollo cognitivo en la edad adulta y la vejez" EN J. Palacios, A. Marchesi y C. Coll (Eds.), Desarrollo psicológico y educación 1. Psicología evolutiva 545-566. Madrid: Alianza.

Vygotsky, L.S. (1978). Mind in Society. Harvard University Press: Cambridge.

Wang, M. C. \& Walberg, H. J (1983). Adaptive Instruction and Classroom Time. EN Adaptive Instruction and Classroom Time American Educational Research Journal, 4 (20), 601-626.

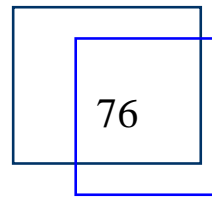

Félix Huelves Martín

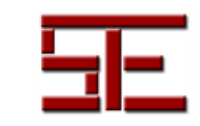




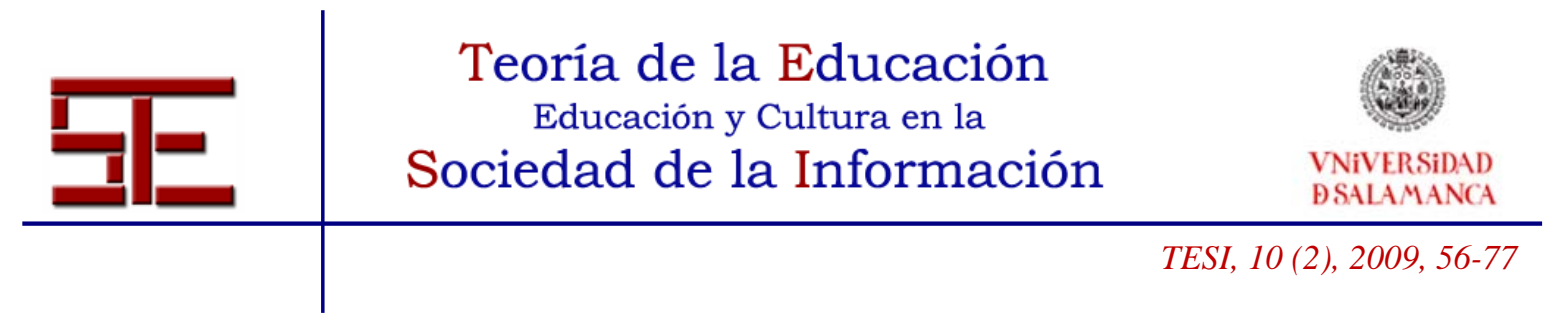

Para citar la presente editorial puede utilizar la siguiente referencia:

Huelves Martín, F. (2009). Buenas prácticas TIC. La alfabetización digital en mayores, en Ortega Sánchez, I. Ferrás Sexto, C. (Coord.) Alfabetización Tecnológica y desarrollo regional [monográfico en línea]. Revista Electrónica Teoría de la Educación: Educación y Cultura en la Sociedad de la Información. Vol. 10, $\mathrm{n}^{0}$ 2. Universidad de Salamanca [Fecha de consulta: dd/mm/aaaa].

http://campus.usal.es/ revistas_trabajo/index.php/revistatesi/article/view/7508/7539

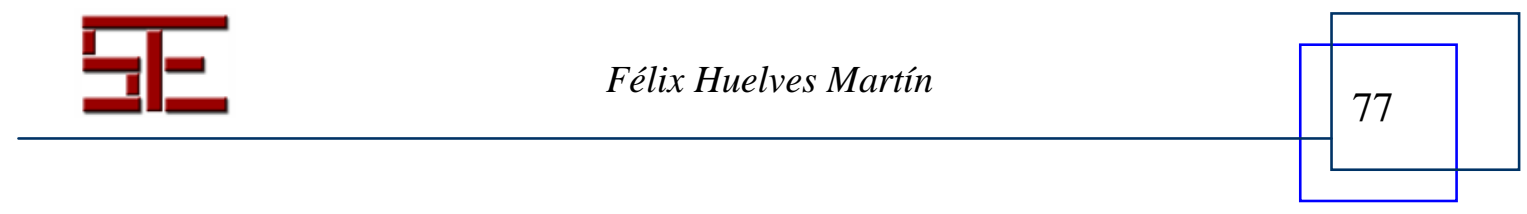

